\title{
Correction to: Circular RNA circRNA_0000094 sponges microRNA-223-3p and up-regulate F-box and WD repeat domain containing 7 to restrain $T$ cell acute lymphoblastic leukemia progression
}

\author{
Yan Hou ${ }^{1} \cdot$ Junjie Sun ${ }^{1} \cdot$ Jie Huang ${ }^{1} \cdot$ Fengzhi Yao ${ }^{1} \cdot$ Xuelian Chen ${ }^{1} \cdot$ Bin Zhu ${ }^{1}$ (D)
}

Published online: 6 July 2021

(C) Japan Human Cell Society 2021

\section{Correction to: Human Cell (2021) 34:977-989 \\ https://doi.org/10.1007/s13577-021-00504-4}

In the original publication of the article, the co-corresponding and last author "Dongchi Zhao" should be removed from the author group. The author group and affiliations are updated in this correction.

Publisher's Note Springer Nature remains neutral with regard to jurisdictional claims in published maps and institutional affiliations.

The original article can be found online at https://doi.org/10.1007/ s13577-021-00504-4.

Bin Zhu

Zhubin2020sci@163.com

1 Department of Pediatrics, Xiangyang Central Hospital, Affiliated Hospital of Hubei University of Arts and Science, No. 136 Jingzhou Street, Xiangcheng District, Xiangyang City 441021, Hubei Province, China 